\title{
Polarização da cárie em município sem água fluoretada
}

\author{
Polarization of dental caries in a Brazilian \\ city without fluoridated water
}

\begin{abstract}
Luciana Cardoso 1
Cassiano Rösing 1

Paulo Kramer 1

Carolina Covolo da Costa 2

Luiz Cesar da Costa Filho 3
\end{abstract}

\footnotetext{
1 Departamento de Odontologia, Universidade Luterana do Brasil. Rua Miguel Tostes 101 Canoas, RS 92420-280, Brasil. cardosoluciana@hotmail.com ckrosing@hotmail.com paulokramer@hotmail.com 2 Centro de Ciências da Saúde, Universidade Federal de Santa Catarina. C.P. 476, Florianópolis, SC 88040-900, Brasil. caucosta@yahoo.com 3 Departamento Clínico, Faculdade de Odontologia, Pontifícia Universidade Católica do Rio Grande do Sul. Av. Ipiranga 6681, Porto Alegre, RS 90619-900, Brasil. periodontia@rocketmail.com
}

\begin{abstract}
Increased overall exposure of the Brazilian population to fluoridated water and fluoridated dentifrices has been identified as the main factor in the reduction of caries prevalence. Thus, the objective of the present study was to evaluate the distribution of caries in a group of 437 children ranging from 6 to 12 years of age, residing in a city without a water supply fluoridation system and without a preventive dentistry program, with the aim of orienting future health measures towards improved cost-effectiveness. Clinical examination was performed on all the children, focusing on the indices defs (decayed, extracted, and filled primary dentition surfaces) and DMFS (decayed, missing, and filled permanent dentition surfaces), representing the number of dental surfaces that were either decayed, missing or with extraction indicated, or restored. Analysis of accumulated disease frequency in relation to the population showed that $37 \%$ of the children presented 70\% of all the tooth disease, with a mean defs + DMFS of 28.6. This distribution demonstrates the phenomenon of polarization, in which most of the disease and treatment needs are concentrated in a small portion of the population.
\end{abstract}

Key words DMF Index; Dental Caries; Oral Health

Resumo A maior exposição da população brasileira ao flúor da água e dos dentifrícios fluoretados tem sido apontada como principal responsável pela redução da prevalência de cárie. Dessa forma, o objetivo do presente trabalho foi avaliar a distribuição da cárie em uma população de 437 crianças, com idades entre 6 e 12 anos, residentes em uma cidade sem sistema de fluoretação da água de abastecimento e sem programa odontológico preventivo, podendo, com isso, orientar futuras ações de saúde com melhor desempenho no que diz respeito à relação custo-efetividade. Para tanto, foi realizado exame clínico em todas as crianças para avaliação dos índices CPO-S e ceo-s, o que representa o número de superfícies dentárias cariadas, perdidas ou com extração indicada e restauradas. A análise de freqüência acumulada da doença em relação à freqüência acumulada da população mostrou que $37 \%$ das crianças concentravam $70 \%$ da doença, com um ceo-s + CPO-S médio de 28,6. Essa distribuição evidencia o fenômeno da polarização, no qual uma pequena parcela da população concentra a maior parte da doença e das necessidades de tratamento.

Palavras-chave Índice CPO; Cárie Dentária; Saúde Bucal 


\section{Introdução}

Nos últimos anos, têm-se observado expressivos ganhos nos níveis de saúde bucal na maioria dos países industrializados e entre alguns daqueles em processo de desenvolvimento (Oliveira et al., 1995). Os levantamentos epidemiológicos realizados no Brasil mostraram um declínio na experiência de cárie (medida pelo CPO-D - dentes cariados perdidos e obturados) na população infantil entre 1986 e 1993.

Em 1986, o CPO-D aos 12 anos de idade foi de 6,65, ou seja, uma prevalência de cárie muito alta segundo a Organização Mundial da Saúde (OMS). Já em 1993, o levantamento epidemiológico realizado pelo Serviço Social da Indústria (SESI) indicou uma média geral do CPO-D aos 12 anos de 4,84, o que representa uma queda de $27,2 \%$ em relação aos dados apresentados sete anos antes. Em 1996, um levantamento epidemiológico de saúde bucal (cárie dental) realizado em todas as capitais brasileiras apontou um CPO-D médio de 3,06 aos 12 anos de idade, o qual estava bastante próximo da meta estabelecida para o ano 2000 pela OMS (CPO-D $\leq 3,0$ aos 12 anos). Quando os três levantamentos epidemiológicos brasileiros são analisados mais detalhadamente, observa-se uma tendência à polarização na distribuição da doença, isto é, os valores mais altos do CPO-D concentraram-se em um reduzido número de indivíduos (Oliveira, 1998).

Os fatores apontados como prováveis responsáveis pelo declínio na prevalência de cárie no Brasil são: o aumento e a universalização da exposição das pessoas ao flúor em suas variadas formas de aplicação, com destaque especial para a água de abastecimento e os dentifrícios fluoretados, a maior ênfase nas atividades de promoção de saúde, a melhoria nas condições globais de saúde e qualidade de vida e a mudança nos critérios de diagnóstico de cárie (Narvai et al., 2000; Oliveira, 1998; Winter, 1990). No entanto, certas comunidades brasileiras não foram beneficiadas da mesma maneira por esse implemento na saúde bucal, pois existem determinadas características presentes nas mesmas, como ausência de fluoretação da água de abastecimento, falta de acesso a programas preventivos e baixo nível sócio-econômicocultural, que tornam as pessoas suscetíveis a concentrarem níveis mais elevados da doença cárie.

Como o aumento do contato das populações com o flúor, sob as suas mais variadas formas, é considerado um dos principais responsáveis pela acentuada redução na prevalência e na severidade da doença cárie, as pessoas que não têm acesso a ele e/ou a programas preventivos de saúde bucal constituem os chamados grupos de alto risco, que acabam concentrando os mais altos níveis de cárie dentária e, dessa forma, polarizando a distribuição da doença. Esse fenômeno, conhecido como polarização, consiste na concentração da maior parte das doenças e das necessidades de tratamento em uma pequena parcela da população (Martins et al., 1985; Weyne, 1997).

Tendo em vista a escassez de dados na literatura em relação à prevalência de cárie dentária em cidades do interior do Brasil, uma vez que o último levantamento epidemiológico foi realizado apenas nas capitais, o objetivo do presente trabalho foi avaliar a distribuição da doença em uma população infantil sem acesso à água fluoretada e aos programas preventivos de saúde bucal, de modo a orientar futuras ações de saúde e otimizar a relação custo-efetividade dos programas odontológicos.

\section{Materiais e método}

O estudo foi realizado no ano de 1998 e envolveu todas as escolas pertencentes ao Município de Pareci Novo, Rio Grande do Sul, totalizando cinco escolas, sendo três delas municipais, uma particular e uma estadual. O referido município não apresentava sistema de fluoretação da água de abastecimento público e nem programas preventivos de saúde bucal. Assim, o grupo estudado recebia apenas tratamento odontológico restaurador.

A população de escolares de Pareci Novo é constituída por 520 alunos, dos quais 437 participaram do estudo por terem entre 6 e 12 anos de idade (83 crianças com seis anos; 44 com sete; 53 com oito; 61 com nove; 47 com dez; 56 com 11 e 93 com 12 anos), sendo 230 do sexo masculino e 207 do sexo feminino.

Os exames foram realizados nas próprias dependências das escolas, utilizando duas carteiras escolares justapostas, como cadeira odontológica, e uma cadeira, como mocho.

Todos os dentes presentes na cavidade bucal da criança foram examinados, sendo excluídos apenas aqueles que não estivessem completamente irrompidos, de forma a facilitar o exame clínico e minimizar os erros de diagnóstico. O número total de superfícies computadas, válidas no estudo, é mostrado na Tabela 1.

Todos os exames clínicos foram realizados por uma cirurgiã-dentista com auxílio de uma anotadora. Para tanto, foi efetuada a calibração visando a verificar o nível de concordância entre as leituras de um mesmo evento e, dessa for- 
ma, tornar o resultado o mais semelhante e uniforme possível. A calibração obteve um Kappa de 0,80 nos reexames.

Os índices escolhidos para avaliar a prevalência de cárie foram o CPO-S e o ceo-s através da avaliação de cada superfície dos dentes permanentes e decíduos, classificando-a em cariada, perdida ou com extração indicada e obturada. Quando um dente anterior era considerado perdido ou com extração indicada, quatro superfícies eram diagnosticadas como tal; caso fosse um dente posterior, cinco superfícies eram consideradas perdidas. A escolha desses índices baseou-se no fato de os mesmos serem mais detalhados que o CPO-D e o ceo-d (cariado, extraído e obturado, considerando o dente decíduo permanente), possibilitando uma análise mais acurada da real situação bucal das crianças avaliadas.

O exame clínico foi realizado com a criança deitada sobre as carteiras escolares, utilizando-se espelho bucal plano no 5 , sonda periodontal, lanterna e pêra de ar, com objetivo de facilitar os exames, melhorando a visualização dos dentes, e reduzir os custos. Os dados foram computados somando-se o número de superfícies cariadas, perdidas ou com extração indicada e restauradas e, após, dividindo-se pelo número total de superfícies existentes.

A realização deste estudo foi condicionada ao cumprimento dos princípios éticos contidos na Resolução Conselho Nacional de Saúde 196/96 (CNS, 1996) e suas complementares, e todas as crianças possuíam autorização de seus pais/responsáveis para participar da pesquisa.

\section{Resultados}

A distribuição da cárie dentária na população estudada foi evidenciada através de gráficos de freqüência acumulada, os quais facilitam a visualização dos grupos nos quais as intervenções seriam mais custo-efetivas. Nesse tipo de gráfico, é possível fazer uma relação direta entre o percentual acumulado de crianças (eixo x) e o percentual acumulado de doença (eixo y).

A linha 4 corresponde à distribuição padrão da doença em população hipotética e é obtida quando o percentual acumulado de crianças corresponde ao percentual acumulado de doença. Tem-se este tipo de distribuição quando não há polarização e, assim, $50 \%$ das crianças detêm $50 \%$ da doença, por exemplo.

A curva 3 representa a prevalência total de cárie nas crianças, pois, como é constituída pela soma dos índices CPO-S e ceo-s, tem-se o número de superfícies cariadas, perdidas e res-

\begin{tabular}{|c|c|c|c|c|}
\hline \multicolumn{5}{|c|}{$\begin{array}{l}\text { Número de superfícies por idade, sexo e tipo de dentição. Pareci Novo, } \\
\text { Rio Grande do Sul, Brasil, } 1998 .\end{array}$} \\
\hline \multirow{2}{*}{$\begin{array}{l}\text { Idade } \\
\text { (anos) }\end{array}$} & \multicolumn{2}{|c|}{ Dentição decídua } & \multicolumn{2}{|c|}{ Dentição permanente } \\
\hline & Sexo feminino & Sexo masculino & Sexo feminino & Sexo masculino \\
\hline 6 & 3.246 & 3.293 & 124 & 112 \\
\hline 7 & 1.211 & 1.613 & 320 & 376 \\
\hline 8 & 1.252 & 1.556 & 787 & 940 \\
\hline 9 & 1.180 & 1.165 & 1.921 & 1.191 \\
\hline 10 & 440 & 776 & 1.531 & 1.690 \\
\hline 11 & 110 & 519 & 2.410 & 2.568 \\
\hline 12 & 133 & 307 & 4.238 & 5.127 \\
\hline Total & 7.572 & 9.229 & 11.331 & 12.004 \\
\hline
\end{tabular}

tauradas dos dentes permanentes e decíduos da referida população.

A curva 1 evidencia o percentual acumulado do índice CPO-S, ou seja, apenas as superfícies cariadas, perdidas e restauradas dos dentes permanentes.

A curva 2 corresponde ao percentual acumulado da doença em dentes decíduos, pois apenas o índice ceo-s é levado em consideração.

Nos padrões epidemiológicos atuais, a polarização para a cárie dentária é aquela em que cerca de $70 \%$ dos dentes afetados pela doença estão em 30\% das crianças (Nadanovsky, 2000). Portanto, para que possam ser feitas comparações entre a distribuição de cárie na população estudada e os dados da literatura, o percentual de $70 \%$ de concentração da doença foi usado como base para descrever a polarização nas crianças de Pareci Novo, Rio Grande do Sul.

A Figura 1 representa a distribuição da cárie dentária em todas as crianças avaliadas que possuíam entre 6 e 12 anos de idade. Através do referido gráfico, pode-se constatar que $37 \%$ da população concentram $70 \%$ do número total de dentes decíduos e permanentes cariados, perdidos e restaurados, com CPO-S + ceos médio de 28,6. Em relação ao percentual acumulado dos índices CPO-S e ceo-s, avaliados separadamente, $37 \%$ das crianças concentram 91,3\% de cárie nos dentes permanentes, enquanto este mesmo percentual da população, que não corresponde necessariamente às mesmas crianças, acumulam $80,3 \%$ da doença nos dentes decíduos.

A Figura 2 ilustra a distribuição da cárie dentária nas crianças com seis anos de idade. Por causa da idade, a grande maioria dos dentes avaliados eram decíduos, podendo-se notar que o percentual acumulado total de cárie 
Figura 1

Distribuição da doença cárie em todas as crianças avaliadas.

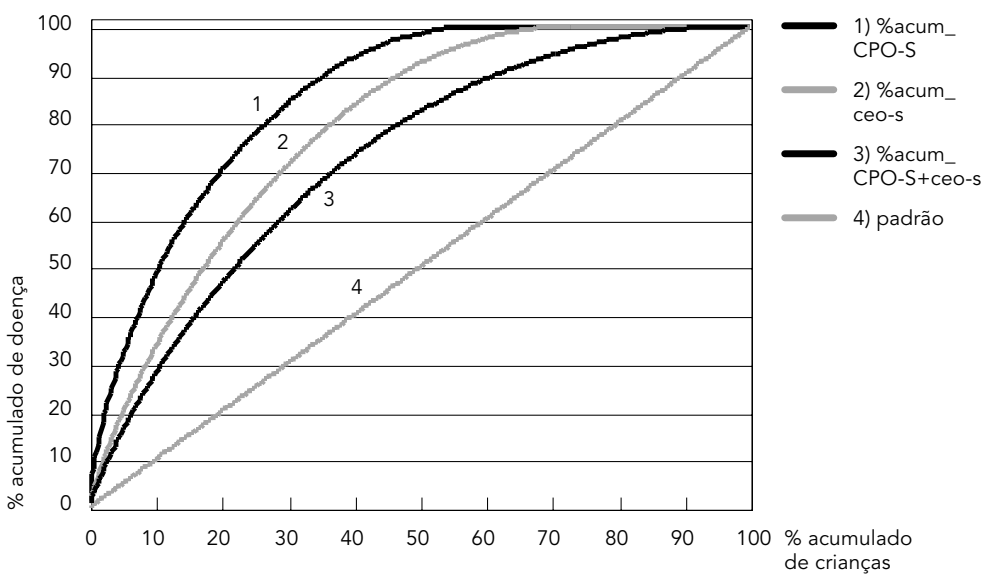

Figura 2

Distribuição da doença cárie nas crianças de seis anos.

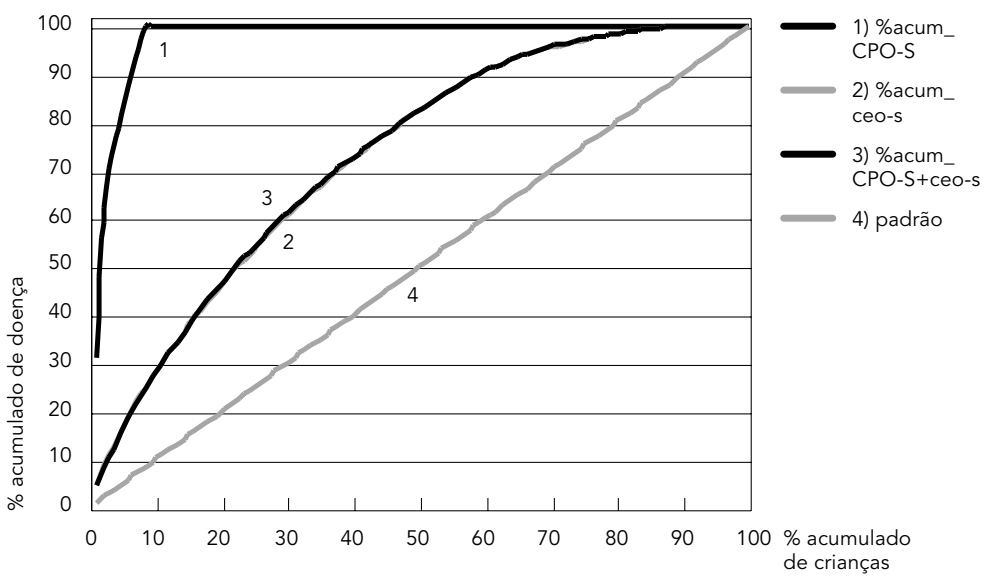

(CPO-S + ceo-s) é praticamente coincidente com o percentual acumulado da doença para os referidos dentes (ceo-s), pois as curvas 3 e 2 estão sobrepostas. Logo, 37,5\% da população concentram $70 \%$ de superfícies cariadas, perdidas e restauradas em dentes decíduos e permanentes, com CPO-S + ceo-s médio de 33,2. Como, aos seis anos de idade, a maioria das crianças não apresentava dentes permanentes ou estes não foram considerados por não estarem totalmente irrompidos, a percentagem to- tal da doença nos referidos dentes foi encontrada em apenas $8,5 \%$ da população.

Nas idades de sete e oito anos, a situação evidenciada é semelhante à dos seis anos de idade, pois, da mesma forma, a maioria dos dentes considerados na avaliação eram decíduos. Assim, 40,9\% das crianças com sete anos concentram $69,3 \%$ das superfícies cariadas, perdidas e restauradas do total de dentes permanentes e decíduos, com CPO-S + ceo-s médio de 33,8. A distribuição da cárie dentária na população de oito anos de idade demonstra que a coincidência do percentual acumulado da doença para dentes permanentes e decíduos (CPO-S + ceo-s) e somente para dentes decíduos (ceo-s) continua evidente. Sendo assim, $39,6 \%$ dos indivíduos concentram $68,9 \%$ da doença em dentes decíduos e permanentes, com CPO-S + ceo-s médio de 31,6.

Na Figura 3, que representa a distribuição da cárie dentária aos nove anos de idade, pode-se notar que $39,2 \%$ da população concentram $69,2 \%$ da doença, com CPO-S + ceo-s médio de 27,5. Aos dez anos de idade, 38,3\% da população apresentam $68,9 \%$ das seqüelas da doença, com CPO-S + ceo-s médio de 25,7.

Nas idades de 11 e 12 anos, as curvas de percentual acumulado para dentes permanentes e decíduos (CPO-S + ceo-s) e somente para dentes permanentes (CPO-S) coincidem em diversos pontos, pois o número de dentes permanentes avaliados é maior que o de decíduos devido ao processo de exfoliação fisiológica. Assim, aos 11 anos, 35,5\% da população concentram $71,4 \%$ de cárie, com CPO-S + ceo-s médio de 23,6. De acordo com o Gráfico 4, aos 12 anos, $37,6 \%$ da população concentram $70,8 \%$ da doença, com CPO-S + ceo-s médio de 20,1, e, nesta mesma percentagem de crianças, o percentual acumulado do índice CPO-S corresponde a 72,3\%. Como o número de dentes decíduos avaliados foi reduzido, $100 \%$ das superfícies dentárias decíduas cariadas, perdidas e restauradas estavam concentradas em $24,7 \%$ das crianças.

O percentual de crianças com CPO-S + ceo-s igual a zero no quadro geral, ou seja, para toda população de 6 a 12 anos, foi de $6,28 \%$. Para as idades de seis, sete, oito, nove, dez, 11 e 12 anos, o percentual de crianças livres de cárie foi de $8,5 \%, 2,27 \%, 1,89 \%, 3,28 \%, 6,39 \%, 7,15 \%$ e $3,22 \%$, respectivamente.

\section{Discussão}

A cárie dentária é uma doença crônica que constitui um dos grandes problemas de saúde 
pública no Brasil e atinge indivíduos de todas as faixas etárias e níveis sócio-econômicos.

Embora no Brasil a fluoretação seja o componente essencial de um programa preventivo abrangente e exista, desde 1975, uma lei que obriga todas as cidades a implantarem o sistema de fluoretação da água de abastecimento público, muitos municípios no interior do País são privados desse benefício. Este é o caso de Pareci Novo, no Rio Grande do Sul, que não possuía, na época do estudo, sistema de fluoretação da água, já que a mesma era fornecida à comunidade através de dois poços artesianos, nem programa preventivo de saúde bucal. Dessa forma, a população, além de ser privada do acesso ao flúor via água de abastecimento e programas de prevenção, só contava com o atendimento curativo para solucionar suas necessidades odontológicas.

Por intermédio da presente pesquisa, foi possível evidenciar a ocorrência de polarização da cárie dentária em crianças de 6 a 12 anos que residem em uma cidade sem água fluoretada, pois $37 \%$ delas detinham cerca de $70 \%$ da doença. Se o percentual acumulado de crianças, no valor de $20 \%$, fosse considerado, haveria uma concentração de $46,5 \%$ de cárie nessa parcela da população. Esses dados contrariam o estudo de Margolis (1994), no qual 20\% das crianças residentes em Portland e em Aiken, cidades sem água fluoretada e sem programa de aplicação de flúor nas escolas, concentravam $75 \%$ e $60 \%$ da doença, respectivamente. Esse fato pode ser explicado pela natureza multifatorial da cárie, já que, embora a cidade brasileira e as cidades americanas tivessem uma variável comum, que é a falta de acesso a fontes de flúor, existem outros fatores importantes no processo saúde/doença que não foram avaliados, como padrão de higiene bucal, microbiota da placa bacteriana, hábitos alimentares, condições sócio-econômicas, entre outros.

Considerando a distribuição da cárie nas diferentes idades avaliadas, foi possível evidenciar que, aos seis, sete e oito anos, existe uma coincidência entre as curvas que representam o percentual acumulado da doença em dentes decíduos (ceo-s) e em dentes permanentes e decíduos (CPO-S + ceo-s). Essa distribuição pode ser explicada pelo fato de crianças nesta faixa etária apresentarem, em sua maioria, apenas dentes decíduos ou permanentes fora de oclusão funcional (não considerados na computação dos dados).

Em relação às idades de 11 e 12 anos, é evidente que existe uma distribuição semelhante do percentual acumulado em dentes permanentes (CPO-S) e em dentes permanentes e de-
Figura 3

Distribuição da doença cárie nas crianças de nove anos.

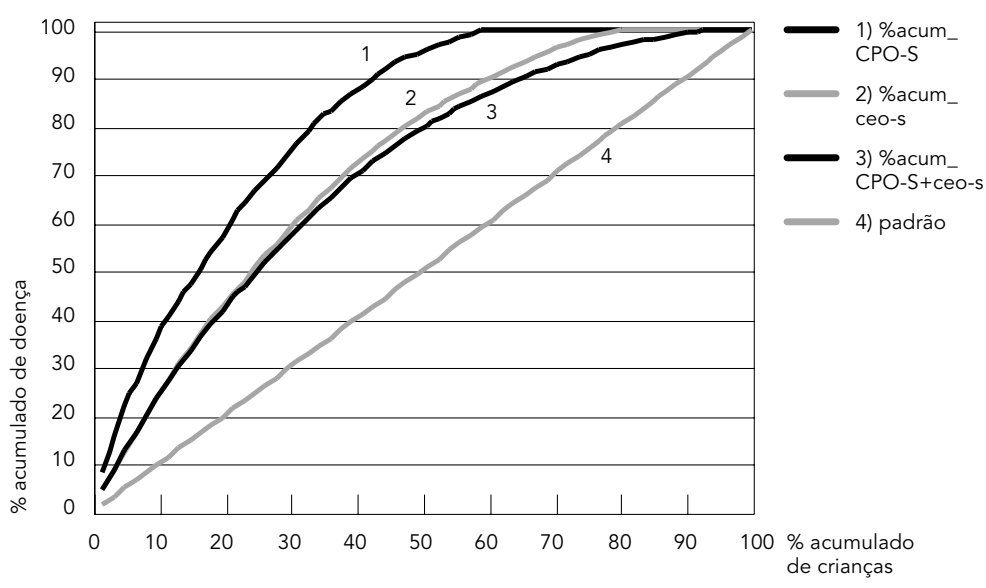

Figura 4

Distribuição da doença cárie nas crianças de 12 anos

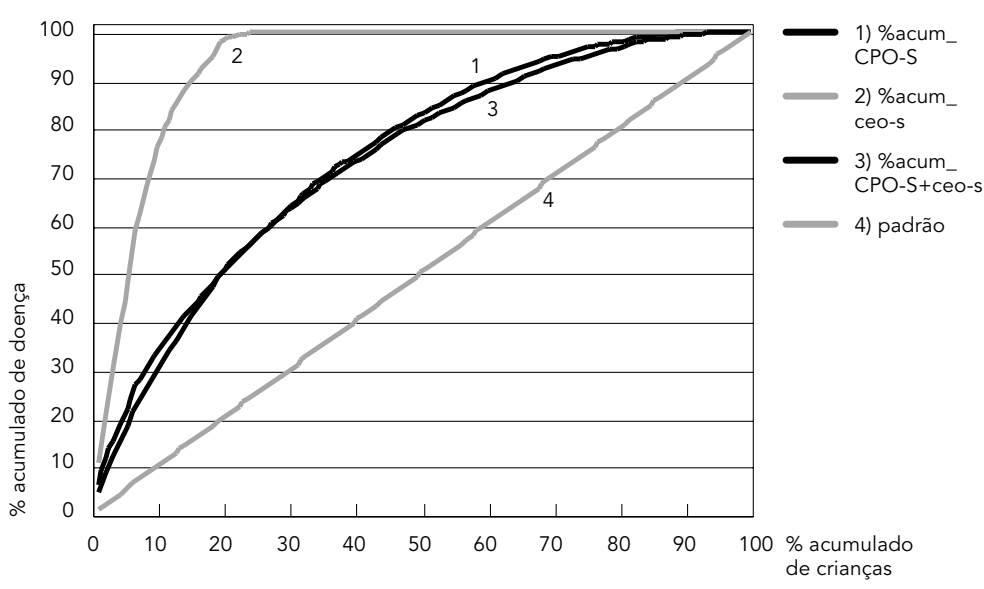

cíduos (CPO-S + ceo-s) devido à coincidência das curvas. Isso se deve à predominância de dentes permanentes na cavidade bucal das crianças nestas idades, uma vez que, entre $11 \mathrm{e}$ 12 anos, a grande maioria dos dentes decíduos já sofreu processo de exfoliação fisiológica.

De acordo com o presente estudo, a idade que apresentou maior polarização da doença cárie foi a de 11 anos, na qual 35,5\% das crianças concentram $71,4 \%$ das superfícies cariadas, perdidas e restauradas em dentes decíduos e 
permanentes (ceo-s + CPO-S). Esse dado contraria o estudo de Kukleva \& Kondeva (1999), que constataram ser a idade de sete anos a que apresenta maior polarização da cárie.

O percentual de crianças livres de cárie entre 6 e 12 anos no Município de Pareci Novo, Rio Grande do Sul, foi de 6,28\%. Este valor é extremamente inferior àqueles encontrados para crianças de mesma faixa etária que residem em cidades com sistema de fluoretação da água. No estudo de Viegas \& Viegas (1985), feito em Campinas, São Paulo, que possuía água fluoretada há 14 anos na época da pesquisa, 26\% das crianças apresentavam todos os dentes hígidos. Já Santos et al. (1998) relataram um percentual de crianças livres de cárie semelhante ao encontrado no presente estudo (5,3\%), quando uma população da mesma faixa etária, sem acesso ao flúor e a programas preventivos foi analisada.

Ainda em relação ao percentual de crianças livres de cárie nas diferentes idades avaliadas, é possível verificar que aos 6 e aos 12 anos os valores foram de $8,5 \%$ e $3,22 \%$, respectivamente. O dado referente aos seis anos de idade contraria o estudo de Saliba et al. (1998), feito em uma cidade com água fluoretada, no qual $40,4 \%$ das crianças estavam livres da doença. O estudo de Freire et al. (1999) também encontrou um valor baixo $(4,4 \%)$ para crianças livres de cárie aos 12 anos, pois a população, à semelhança dos escolares de Pareci Novo, Rio Grande do Sul, não tinha acesso a medidas educativas e preventivas em saúde bucal.
Considerando os índices CPO-S e ceo-s conjuntamente para os escolares de Pareci Novo, Rio Grande do Sul, é evidente a diminuição no número total de superfícies cariadas, perdidas e restauradas em dentes decíduos e permanentes com o aumento da idade, sendo o valor do CPO-S + ceo-s de 33,2, aos seis anos de idade, e de 20,1, aos 12 anos. Uma provável explicação para isso é que, como os dentes decíduos estavam mais afetados pela doença que os permanentes, à medida que foram exfoliando, o valor de CPO-S + ceo-s diminuiu.

Por meio do presente estudo, foi possível identificar a ocorrência de polarização da doença cárie nos escolares de Pareci Novo, Rio Grande do Sul. Portanto, com a identificação das crianças que apresentam maior experiência de cárie (alto índice CPO-S + ceo-s), tem-se o melhor indicador da ocorrência da doença no futuro e, assim, podem ser feitas previsões quanto às estratégias preventivas que devem ser implantadas na população em questão, principalmente no grupo que acumula maior quantidade da doença (Nadanovsky, 2000). Com o reconhecimento das crianças afetadas pela cárie, é possível aplicar uma estratégia específica a esse grupo, a fim de economizar recursos financeiros e tempo, visto que os mesmos seriam direcionados à parcela da população que apresenta maiores necessidades de prevenção e tratamento.

\section{Referências}

CNS (Conselho Nacional de Saúde), 1996. Resolução 196 de 1996. Diretrizes e Normas Regulamentadoras de Pesquisas Envolvendo Seres Humanos. 10 Março 2002 <http:/ /www.ufrgs.br/HCPA/gppg/ res19696.htm>.

FREIRE, M. C. M.; PEREIRA, M. F.; BATISTA, S. M. O.; BORGES, M. R. S.; BARBOSA, M. I. \& ROSA, A. G. F., 1999. Prevalência de cárie e necessidades de tratamento em escolares de 6 a 12 anos da rede pública de ensino. Revista de Saúde Pública, 33: 385-390. 
KUKLEVA, M. \& KONDEVA, V., 1999. Comparative study of the polarization of dental caries in 7, 12and 14-year-old children from Plovdiv, Bulgaria. Folia Medica, 41:65-70.

MARGOLIS, M. Q., 1994. Distribution of primary tooth caries in first-grade children from two nonfluoridated US communities. Pediatric Dentistry, 16:200-205.

MARTINS, L. H. P. M.; PARREIRA, M. L. J. \& RIBEIRO, J. C. C., 1985. Prevalência de cárie em dentes decíduos de escolares beneficiados e não pelos fluoretos. Arquivos do Centro de Estudos do Curso de Odontologia, 22:87-100.

NADANOVSKY, P., 2000. O declínio da cárie. In: Saúde Bucal Coletiva (V. G. Pinto, org.), pp. 341-351, São Paulo: Editora Santos.

NARVAI, P. C.; CASTELLANOS, R. A. \& FRAZÄO, P., 2000. Prevalência de cárie em dentes permanentes de escolares do Município de São Paulo, SP, 1970-1996. Revista de Saúde Pública, 34:196200.

OLIVEIRA, A. G. R. C., 1998. Perfil Epidemiológico de Saúde Bucal no Brasil 1986-1996. Setembro 1998 <http://www.angelonline.cjb.net>.

OLIVEIRA, C. M. B.; ASSIS, D. F. \& FERREIRA, E. F. E., 1995. Avaliação da fluoretação da água de abastecimento público de Belo Horizonte, MG, após 18 anos. Revista do Conselho Regional de Odontologia de Minas Gerais, 1:62-66.
SALIBA, N. A.; ORENHA, E. S.; NAKAMA, L.; MENEGHIM, M. C. \& MOIMAZ, S. A. S., 1998. Prevalência da cárie dentária em crianças de 3 a 6 anos de idade, do Município de Araçatuba - SP, 1996. Revista da Faculdade de Odontologia da UNESP, 27:207-13.

SANTOS, V. B.; LENZA, M. A. \& FREIRE, M. C. M., 1998. Experiência de cárie e situação de higiene oral em crianças dos orfanatos de Anápolis - GO. ROBRAC, 7:16-19.

VIEGAS, Y. \& VIEGAS, A. R., 1985. Prevalência de cárie dental na cidade de Campinas, SP, Brasil, depois de quatorze anos de fluoração da água de abastecimento público. Revista da Associação Paulista dos Cirurgiões-Dentistas, 39:272-282.

WEYNE, S. C., 1997. A construção do paradigma de promoção de saúde - Um desafio para as novas gerações. In: ABOPREV - Promoção de Saúde Bucal (L. Kriger, org.), pp. 3-26, São Paulo: Editora Artes Médicas.

WINTER, G. B., 1990. Epidemiology of dental caries. Archives of Oral Biology, 35:1-7.

Recebido em 17 de janeiro de 2002

Versão final reapresentada em 27 de junho de 2002

Aprovado em 19 de agosto de 2002 